\title{
Effect of some peel extracts on the corrosion behavior of aluminum alloy in alkaline medium
}

\author{
Namrata Chaubey ${ }^{1} \cdot \operatorname{Vinod}$ Kumar $\operatorname{Singh}^{1} \cdot$ M. A. Quraishi $^{2}$
}

Received: 28 May 2015/Accepted: 10 September 2015/Published online: 21 September 2015

(c) The Author(s) 2015. This article is published with open access at Springerlink.com

\begin{abstract}
Introduction The inhibition performance of three peels, for instance Pisum sativum (PS), Solanum tuberosum (ST), and Citrus reticulata (CR), on aluminum alloy (AA) in $1 \mathrm{M} \mathrm{NaOH}$ solution was investigated using weight loss, electrochemical impedance spectroscopy (EIS), linear polarization, and potentiodynamic polarization techniques (Tafel).

Results It was found that these three peel extracts exhibit very good performance on AA in alkaline medium. PS exhibited maximum inhibition efficiency $(\eta \%)$ of $94.5 \%$ at $1.5 \mathrm{~g} / \mathrm{L}$. The effective protection of AA in inhibited system was investigated using scanning electron microscopy (SEM) and atomic force microscopy (AFM).

Conclusion The adsorption of inhibitors on AA surface obeyed the Langmuir's adsorption isotherm. Potentiodynamic polarization studies showed mixed mode of corrosion inhibition for all the inhibitors. SEM and AFM complemented well with those obtained from weight loss and electrochemical studies.
\end{abstract}

Keywords Aluminum alloy · EIS · Corrosion inhibition · SEM $\cdot$ AFM

M. A. Quraishi

maquraishi.apc@itbhu.ac.in; maquraishi@rediffmail.com

1 Department of Chemistry, Udai Pratap Autonomous College, Varanasi 221002, India

2 Department of Chemistry, Indian Institute of Technology, Banaras Hindu University, Varanasi 221005, India

\section{Introduction}

Aluminum and its alloys are known as the second largest attractive materials next to iron. AA is currently being used in a broad range of applications due to its low cost, light weight, high thermal and electrical conductivity, aerospace, construction, and electrical power generation. A very good characteristic of AA is its high corrosion resistance behavior toward a wide variety of corrosive environments, because of the formation of a protective, tightly adhered invisible oxide film on the metal surface. But alkaline solution is the most dangerous medium for the corrosion of aluminum among several corrosive media. However, corrosion data are less readily available in this environment [1]. It is therefore desired to study the corrosion inhibition effect on aluminum in alkaline medium. Alkaline solutions are generally used for the removal of undesirable scale and rust in several industrial processes, and metal loss occurs in this medium. The corrosion behavior of AA in alkaline medium has also been extensively studied in the development of the aluminum anode in aluminum-air cell. Self-corrosion is not only responsible for the lower utilization efficiency of aluminum but also for the battery explosion due to severe hydrogen evolution [2]. To improve the efficiency in devices (Al alkaline battery) and various industrial processes such as alkaline cleaning, pickling, and etching, a plenty of organic and inorganic corrosion inhibitors have been used previously [3-7]. But using the compound as an inhibitor is a major drawback because some of them are synthetic chemicals, expensive, and hazardous to the environment.

Thus, it is desirable to develop an environmentally safe corrosion inhibitor, and for this purpose, natural products have been proved as very good inhibitors for aluminum in 
alkaline medium [8-13]. In view of this, we have chosen peels as inhibitors because they are environmentally benign, very cheap, and easily available materials as corrosion inhibiting additives that can be extracted by simple procedure with low cost and also they contain various bioactive compounds having the ability to attach toward corroding metal surfaces. There are few studies available on the use of fruit and vegetable peel extracts as corrosion inhibitors for different metals [14-18], but no report is available on the use of peels as a corrosion inhibitor for aluminum in alkaline medium.

Now, we have collected the peels of some fruits and vegetables. Pisum Sativum peel waste is an outer layer of pea vegetables (family-leguminosae). This is a cool season, annual plant grown in many parts of the world. Solanum Tuberosum (family-Solanaceae) commonly called potatoes are one of the most important staple crops for human consumption, together with wheat, rice, and corn. Citrus reticulata (family-Rutaceae) is commonly called as narangi or santra (orange).

In the present study, we aim to investigate the inhibition effect of aqueous extracts of PS, ST, and CR peels on AA in $1 \mathrm{M} \mathrm{NaOH}$ solution.

\section{Materials and methods}

\section{Preparation of peel extracts solution}

PS, ST, and CR peels were dried in shade, and $5 \mathrm{~g}$ of dried peel powder in $500 \mathrm{ml}$ of $\mathrm{NaOH}$ was taken in a round bottom flask and refluxed for $1 \mathrm{~h}$. The solution was allowed to stand for some time and then filtered. The volume of the filtrate solution was made up to $100 \mathrm{ml}$, which was used as stock solution of inhibitors. The residues of all the peels were then dried to get solid mass and weighed.

\section{Specimen and test solution}

Aluminum alloy coupons were purchased from the market and analyzed it in the Department of Metallurgical Engineering, IIT (BHU). The analytical result revealed the composition of AA specimen (wt\%): Si 0.77, Fe 0.93, $\mathrm{Cu} 0.02$, Mn 0.11, Mg 0.01, Zn 0.01, Cr 0.05, Ti 0.02,

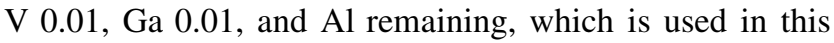
study.

A stock solution of $1 \mathrm{M} \mathrm{NaOH}$ was prepared by dissolving $40 \mathrm{~g}$ of solid $\mathrm{NaOH}$ in double distilled water.

\section{Gravimetric measurement}

AA with the dimension of $2.5 \times 2.0 \times 0.043 \mathrm{~cm}$ was used in the weight loss experiment in $1 \mathrm{M} \mathrm{NaOH}$ solution with and without the addition of different concentrations of peel extracts. For the abrasion of AA coupons, silicon carbide papers with the grades of 600,800 , and 1000 were used, degreased with acetone, dried at room temperature, and weighed.

Every coupon was immersed in solution for $3 \mathrm{~h}$ at $303 \mathrm{~K}$. Thereafter the sample was taken out from the weight loss chamber, washed with distilled water, dried, and weighed.

The same process was repeated at different temperature ranges $(313-333 \mathrm{~K})$. The corrosion rate was calculated using the following relation [19]:

$C_{\mathrm{R}}=\frac{K \times W}{A \times T \times D}$,

where $K$ is a constant $\left(87.6 \times 10^{4}\right), T$ is the exposure time in hours (h), $A$ is the area of a coupon in $\mathrm{cm}^{2}, W$ is the weight loss $(\mathrm{mg})$, and $D$ is the density of AA in $\mathrm{g} / \mathrm{cm}^{3}$

$\eta \%=\frac{w_{0}-w_{i}}{w_{0}} \times 100$,

where $w_{0}$ and $w_{\mathrm{i}}$ are the weight loss values in the absence and presence of inhibitor, respectively.

\section{Electrochemical experiment}

AA coupons used in this experiment were mechanically cut into the dimension of $7.0 \times 1.0 \times 0.043 \mathrm{~cm}$. The electrochemical measurement was carried out by using three-electrode cell assembly connected to the Gamry Potentiostat/Galvanostat (Model 300) at room temperature. AA with $1 \mathrm{~cm}^{2}$ area was used as a working electrode. A platinum foil and a saturated calomel electrode (SCE), i.e., $\left(\mathrm{Cl}^{-}\left|(4 \mathrm{M}) \mathrm{Hg}_{2} \mathrm{Cl}_{2}(s)\right| \mathrm{Hg}(l) \mid \mathrm{Pt}\right.$ ), were used as counter and reference electrodes, respectively. Echem Analyst version 5.0 software packages were used for analyzing the electrochemical data. All the tests were performed after $15 \mathrm{~min}$ immersion of AA in the absence and presence of optimum concentration of inhibitors in1 $\mathrm{M} \mathrm{NaOH}$ solution.

Before starting the impedance experiment, the electrodes were allowed to corrode freely, and its open circuit potential (OCP) was recorded as a function of time for $200 \mathrm{~s}$ to obtain steady-state OCP which corresponds to corrosion potential. Impedance measurements were carried out in the frequency range of $100,000-0.01 \mathrm{~Hz}$ using the AC signals of amplitude $10 \mathrm{mV}$ peak to peak at open circuit potential.

Linear polarization resistance (LPR) measurements were performed in a potential range of -0.02 to $+0.02 \mathrm{~V}$ with respect to OCP at a scan rate of $0.125 \mathrm{mV} / \mathrm{s}$. Finally, potentiodynamic polarization curves were obtained by shifting the electrode potential automatically from -0.25 
to $+0.25 \mathrm{~V}$ vs. OCP at a scan rate of $1 \mathrm{mV} / \mathrm{s}$. The anodic and cathodic curves of the linear Tafel plots were extrapolated to obtain corrosion current densities $\left(I_{\text {corr }}\right)$.

\section{Surface analysis}

The surface study of AA coupons of size $2 \times 2.5 \times 0.046 \mathrm{~cm}$ was analyzed by Scanning electron microscope (SEM) and Atomic force microscope (AFM) by immersing in $1 \mathrm{M} \mathrm{NaOH}$ in the absence and presence of inhibitors for $3 \mathrm{~h}$ at $303 \mathrm{~K}$. The inhibited system contains optimum concentration of CR, ST, and PS peel $(1.5 \mathrm{~g} / \mathrm{L})$. The process was the same as discussed in the weight loss experiment. The samples were investigated using SEM at an accelerating voltage of $5000 \mathrm{~V}$ and $5 \mathrm{KX}$ magnification using FEI Quanta 200F microscope and AFM techniques using NT-MDT multimode, Russia, controlled by a solver scanning probe microscope controller.

\section{Results and discussion}

\section{Weight loss measurements}

\section{Inhibitor concentration}

The effects of addition of different extracts at different concentrations on the AA corrosion in $1.0 \mathrm{M} \mathrm{NaOH}$ solution were studied by weight loss measurement at $303 \mathrm{~K}$ after $3 \mathrm{~h}$ immersion. The inhibition efficiencies $(\eta \%)$ obtained from weight loss measurement are shown in Fig. 1a. It can be shown that the inhibition efficiency of all inhibitors $(\eta \%)$ increases with increasing inhibitor concentration, indicating a decrease in corrosion rate. Maximum $\eta \%$ was obtained $(94.5 \%)$ at optimum concentration $(1.5 \mathrm{~g} / \mathrm{L})$ for PS. From the figure, it is clear that the order of inhibition efficiencies is as follows:

$\mathrm{CR}<\mathrm{ST}<$ PS.

\section{Effect of temperature}

With the concentration, temperature also affects the percentage inhibition efficiency $(\eta \%)$. It can be seen in Fig. $1 \mathrm{~b}$ that $\eta \%$ decreases with rise in temperatures (from 303 to $333 \mathrm{~K}$ ), indicating an increase in corrosion rate. The increase in corrosion rate may be due to an appreciable decrease in the adsorption of the inhibitor molecules on the AA surface with increase in temperature [20]. With decrease in adsorption, more desorption of inhibitor molecules occurs because these two opposite processes are in equilibrium. Due to more desorption of inhibitor molecules at higher temperatures, the larger surface area of AA
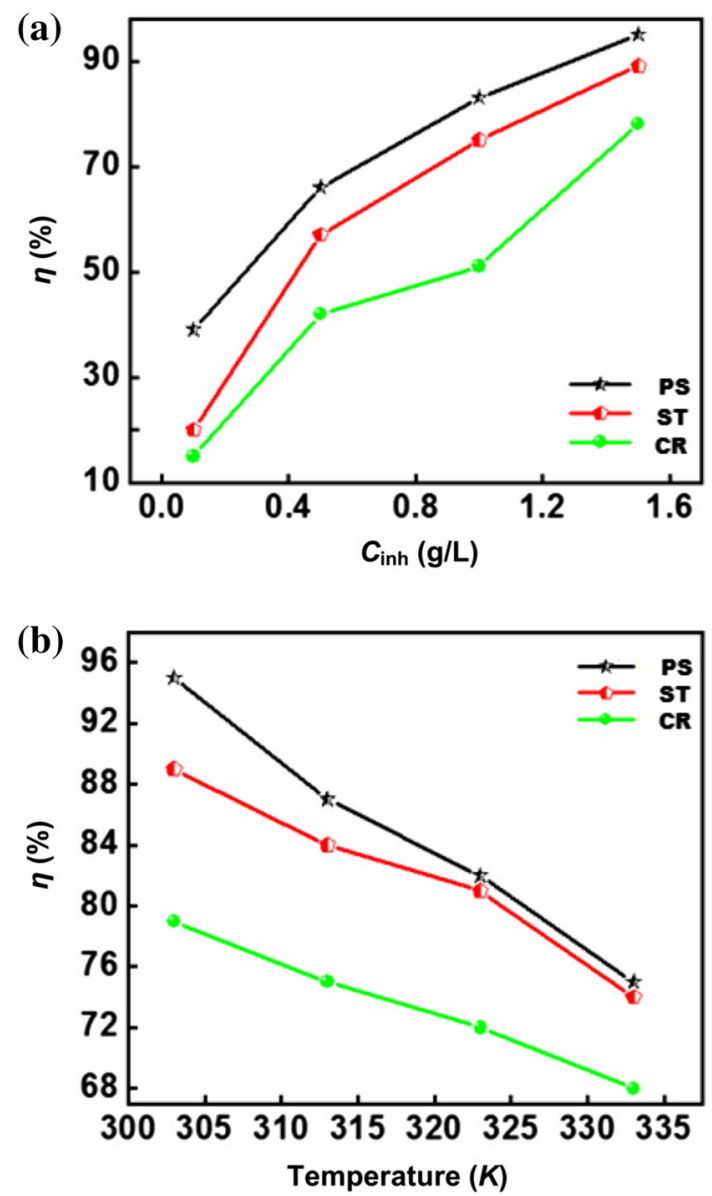

Fig. 1 a Variation of inhibition efficiency $(\eta \%)$ with concentration of peel extracts for AA in $1 \mathrm{M} \mathrm{NaOH}$. b Variation of inhibition efficiency $(\eta \%)$ of inhibitors at optimum concentration at different temperatures (303-333 $\mathrm{K}$ ) in $1 \mathrm{M} \mathrm{NaOH}$

is affected in the alkaline environment, resulting in increased corrosion rates and decreased $\eta \%$ with the increase in temperature.

To calculate the apparent activation energy for corrosion process, Arrhenius Eq. (4) is used [21, 22]:

$\log C_{\mathrm{R}}=\frac{-E_{\mathrm{a}}}{2.303 R T}+\lambda$,

where $E_{\mathrm{a}}$ is the apparent activation energy of the corrosion process, $R$ is the general gas constant, and $A$ is the Arrhenius pre-exponential factor.

The apparent activation energy $\left(E_{\mathrm{a}}\right)$ values at optimum concentration of inhibitors were evaluated by drawing a plot between $\log$ of corrosion rate and $1 / T$ (Fig. 2a). The plot gives a straight line with a slope of $E_{\mathrm{a}} / 2.303 R$. The value of $E_{\mathrm{a}}$ for uninhibited system is $33.6 \mathrm{~kJ} / \mathrm{mol}$ which is much lower than the values for inhibited systems such as PS $(65.9 \mathrm{~kJ} / \mathrm{mol})$, ST $(54.1 \mathrm{~kJ} / \mathrm{mol})$, and CR $(53.9 \mathrm{~kJ} / \mathrm{mol})$.

Higher values of apparent activation energy for inhibited system may be due to the formation of a physical barrier to 

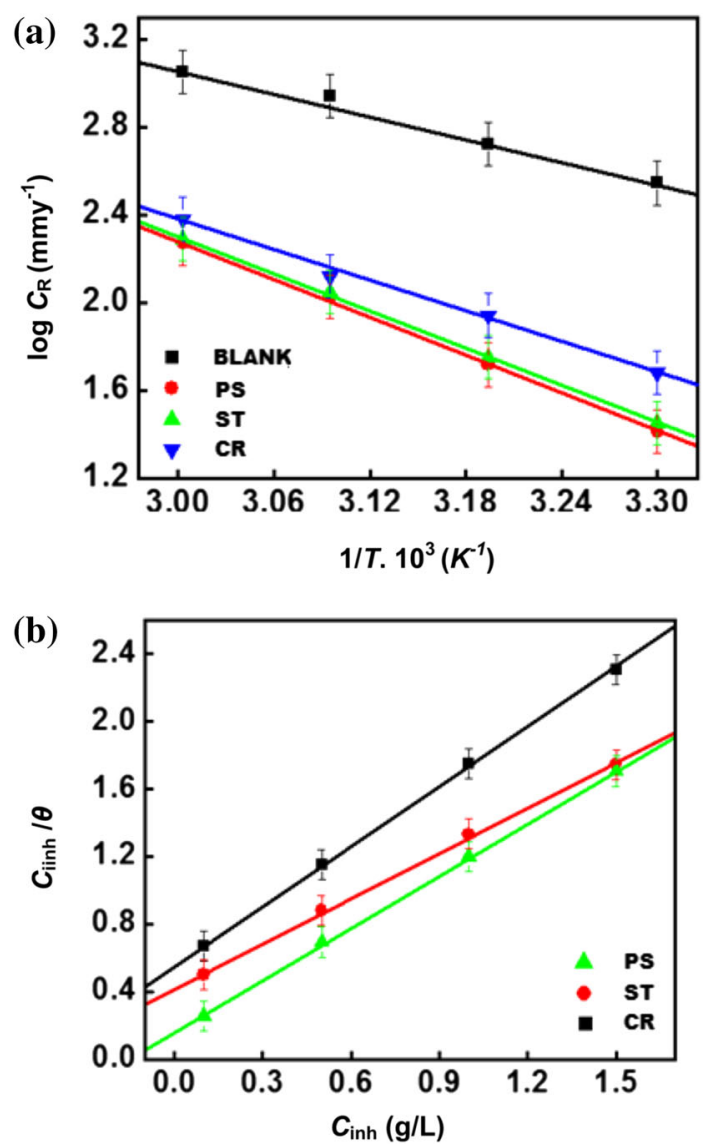

Fig. 2 a Arrhenius plots for AA corrosion rates $(C \mathrm{R})$ in $1 \mathrm{M} \mathrm{NaOH}$ without and with optimum concentration $(1.5 \mathrm{~g} / \mathrm{L})$ of inhibitors. b Langmuir's isotherm plot for adsorption of inhibitors on aluminum in $1 \mathrm{M} \mathrm{NaOH}$

charge and mass transfer created by adsorbed inhibitor molecules. The higher values of $E_{\mathrm{a}}$ in inhibited solution can be explained with the increased thickness of double layer, which enhances the activation energy of the corrosion process.

\section{Adsorption consideration}

To determine the adsorption process, the surface coverage $(\theta)$ values corresponding to various concentrations of inhibitors have been used to explain the correct isotherm. The surface coverage values $(\theta)$ for different inhibitor concentrations were tested by fitting to various isotherms such as Freundlich, Temkin, Langmuir, and Frumkin isotherms [23]. Among these isotherms, Langmuir adsorption isotherm was best fitted (Fig. 2b) and can be given using the following equation:

$\frac{C_{\mathrm{inh}}}{\theta}=\frac{1}{K_{\mathrm{ads}}}+C_{\mathrm{inh}}$,

where $K_{\mathrm{ads}}$ is the adsorption equilibrium constant, $C_{\mathrm{inh}}$ denotes the concentration of the inhibitors, and $\theta$ is a surface coverage value. The plot of $\log C_{\mathrm{inh}} / \theta$ vs. $C_{\mathrm{inh}}$ gives a straight line as shown in Fig. $2 b$, which indicates that the adsorption of inhibitor molecules on the metal surface obeys Langmuir adsorption isotherm.

The values of $K_{\text {ads }}$ obtained from the Langmuir adsorption isotherm are associated with the standard Gibbs free energy of adsorption $\Delta G_{\text {ads }}^{0}$ using the following equation:

$K_{\mathrm{ads}}=\frac{1}{C_{(\text {sol. })}} \exp \left(\frac{\Delta G_{\mathrm{ads}}^{0}}{R T}\right)$,

where $R$ is a universal gas constant, $T$ is the absolute temperature, and $C$ is the concentration of water $(1000 \mathrm{~g} /$ $\mathrm{L})$. The values of $K_{\mathrm{ads}}$ are represented in $\mathrm{g}^{-1} \mathrm{~L}$ here; thus in this equation, the concentration of water is taken in $\mathrm{g} / \mathrm{L}$ (1000 g/L) instead of $55.5 \mathrm{~mol} / \mathrm{L}$.

The values of $K_{\text {ads }}$ and $\Delta G_{\text {ads }}^{0}$ are reported in Table 1. The $K_{\text {ads }}$ value reduces with the increasing temperature, which indicates enhancing the desorption process at elevated temperatures. The literature suggests that the energy values of $\Delta G_{\text {ads }}^{0}$ around $-20 \mathrm{~kJ} \mathrm{~mol}^{-1}$ or less negative indicate an electrostatic interaction between charged inhibitor molecules and charged metal surface, i.e., physisorption, and those of $-40 \mathrm{~kJ} \mathrm{~mol}^{-1}$ or more negative indicate charge sharing or transfer from the inhibitor molecules to the metal surface to form a coordinate type bond, i.e., chemisorptions [24]. The values of $\Delta G_{\text {ads }}^{0}$ range from -36 to $-39 \mathrm{~kJ} \mathrm{~mol}^{-1}$ in our study (Table 1), which reveals the adsorption of inhibitors on aluminum following chemical adsorption (i.e., chemisorption).

The higher values of $K_{\text {ads }}$ and $\Delta G_{\text {ads }}^{0}$ refer to higher adsorption and higher inhibiting effect with increasing exposure time.

\section{Electrochemical measurement}

Impedance study

Impedance spectra for $\mathrm{AA}$ in $1 \mathrm{M} \mathrm{NaOH}$ solution in the absence and presence of optimum concentration of inhibitors are recorded and displayed in the form of Nyquist plot (Fig. 3). It is clearly observed from the plot that the diameter of the semicircle in the case of uninhibited

Table 1 Thermodynamic parameters for the adsorption of inhibitors on AA at optimum concentration in $1 \mathrm{M} \mathrm{NaOH}$ at different temperatures

\begin{tabular}{llll}
\hline Inhibitors & Temperature $(\mathrm{K})$ & $K_{\text {ads }} 10^{3}\left(\mathrm{~g}^{-1}\right)$ & $G_{\text {ads }}^{0}\left(\mathrm{KJmol}^{-1}\right)$ \\
\hline PS & 303 & 6.09 & -39.36 \\
ST & 303 & 2.77 & -37.37 \\
CR & 303 & 1.78 & -36.26 \\
\hline
\end{tabular}




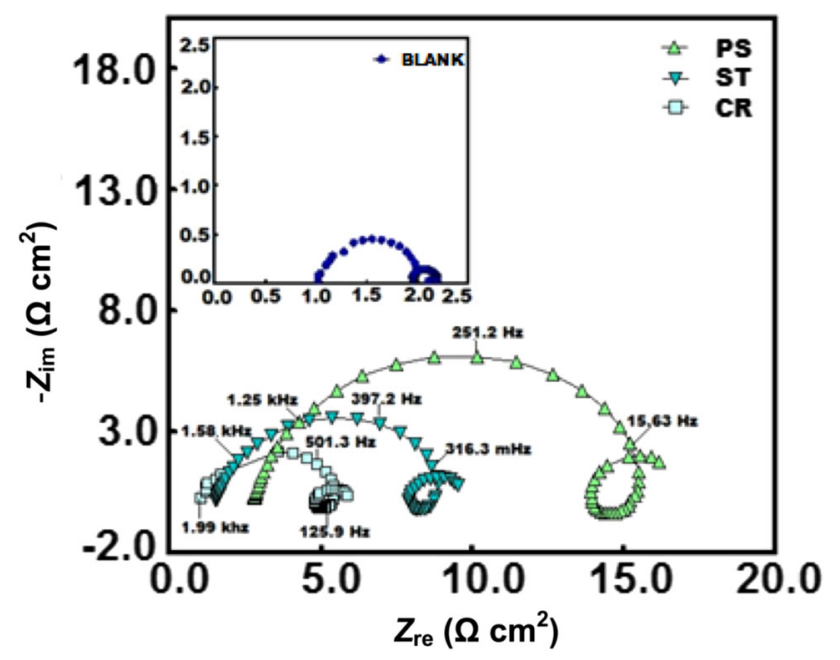

Fig. 3 Nyquist plots of $\mathrm{AA}$ in $1 \mathrm{M} \mathrm{NaOH}$ without and with optimum concentration $(1.5 \mathrm{~g} / \mathrm{L})$ of inhibitors at $303 \mathrm{~K}$

solution is much smaller, but after the addition of inhibitors, it increased significantly due to increasing resistance. The maximum diameter is obtained for PS peel inhibitor at its optimum concentration $(1.5 \mathrm{~g} / \mathrm{L})$ signifying that corrosion is mainly a charge transfer process. Impedance diagram contains three loops which are noticed for AA in alkaline solution, namely a capacitive loop at higher frequency, an inductive loop at medium frequency, and a second capacitive loop at a low-frequency zone. Similar results have been reported in the literature for the corrosion of pure aluminum in alkaline solutions [25, 26]. It should be noticed that these loops are present in the shape of depressed semicircles (not in ideal semicircles), and such behavior may be due to frequency dispersion, surface heterogeneity, and rough-textured metal surface [27]. The first capacitive loop at higher frequency can be due to the charge transfer of the corrosion process and the formation of protective (oxide) layer [28].

From the viewpoint of Brett, the first capacitive loop occurs due to the reaction of aluminum oxidation at the metal/oxide/electrolyte interface $[29,30]$. This process explains the formation of $\mathrm{Al}^{+}$ions at the metal/oxide interface, and their migration through the oxide layer due to high electric field strength to the oxide/solution interface where they are oxidized to $\mathrm{Al}^{3+}$. At the oxide/solution interface, $\mathrm{OH}^{-}$or $\mathrm{O}^{2-}$ ions are also formed. The appearance of the inductive loop is the characteristic feature of these impedance spectra [31]. The existence of inductive loop at intermediate frequency can be attributed either due to the surface roughening or the relaxation process in oxide layer containing adsorbed species such as $\mathrm{OH}_{\text {ads }}^{-}$. Some researchers emphasized on surface roughening because the shifting of inductive loop approaching toward higher frequency depends on hydroxide ion concentration. It can be explained by the fact that due to increasing hydroxide ion concentration, the anhydrous film becomes thinner, the pore diameter becomes wider, and the hydrated layer becomes thicker due to the presence of extensive amount of aluminates and hydroxide species in the solution. Because of the widening of the pore diameter and thinning of the anhydrous film, the chemical and electrochemical dissolution process proceeds easily resulting in surface roughening. The inductive loop shifts toward higher frequency with increasing potential in the positive direction can be attributed to the increasing movement rate of aluminum and hydroxide species and to the enlargement of pores resulting in surface roughening [32]. The second capacitive loop at lower frequency values arises because of the metal dissolution. The similar shape of semicircles for all cases indicates that there is no change in corrosion mechanism occurring through the inhibitors.

All the impedance parameters were calculated (Table 2) with the application of the equivalent circuit model as shown in Fig. 4c. Figure 4a, b clearly explains the fitting of an equivalent circuit model in Nyquist and Bode plot. The circuit contains $R_{\mathrm{S}}$ (the resistance of solution between working electrode and counter electrode), $C_{\mathrm{dl}}$ in parallel to the $R_{\mathrm{ct}}$, and $R_{\mathrm{ct}}$ in series with the parallel inductive elements $L$ and $R_{\mathrm{L}}$. In the impedance spectra, the existence of $L$ in the presence of investigated inhibitors indicated that aluminum is still dissolved by the direct charge transfer at the inhibitor-adsorbed electrode surface [33].

The constant phase element $(C P E)$ is introduced in the circuit rather than a pure double layer capacitance to fit the semicircle more accurately. The impedance for $C P E\left(Z_{\mathrm{CPE}}\right)$ is expressed as

Table 2 Electrochemical impedance parameters for AA in $1 \mathrm{M} \mathrm{NaOH}$ in the absence and presence of optimum concentration of inhibitors at $303 \mathrm{~K}$

\begin{tabular}{|c|c|c|c|c|c|c|c|c|c|c|}
\hline Inhibitors & $\begin{array}{l}R_{\mathrm{S}} \\
(\Omega)\end{array}$ & $\begin{array}{l}Q_{1} \\
\left(\mathrm{~S} \Omega^{-1} \mathrm{~cm}^{-2}\right)\end{array}$ & $n$ & $\begin{array}{l}\left(R_{\mathrm{ct}}\right)_{1} \\
\left(\Omega \mathrm{cm}^{2}\right)\end{array}$ & $L\left(\mathrm{Hcm}^{2}\right)$ & $\begin{array}{l}R_{\mathrm{L}} \\
\left(\Omega \mathrm{cm}^{2}\right)\end{array}$ & $\begin{array}{l}Q_{2} \\
\left(\mathrm{~S} \Omega^{-1} \mathrm{~cm}^{-2}\right)\end{array}$ & $\begin{array}{l}\left(R_{\mathrm{ct}}\right)_{2} \\
\left(\Omega \mathrm{cm}^{2}\right)\end{array}$ & $\begin{array}{l}C_{\mathrm{dl}} \\
\left(\mu \mathrm{F} \mathrm{cm}{ }^{-2}\right)\end{array}$ & $\begin{array}{l}\eta \\
(\%)\end{array}$ \\
\hline Blank & 1.023 & $500 \times 10^{-6}$ & 0.975 & 0.849 & 0.221 & 0.121 & $39.8 \times 10^{-6}$ & 0.188 & 413.8 & - \\
\hline PS & 4.195 & $54.6 \times 10^{-6}$ & 0.976 & 9.90 & 0.030 & 1.947 & $92.2 \times 10^{-6}$ & 8.402 & 73.97 & 91.4 \\
\hline ST & 2.614 & $66.1 \times 10^{-6}$ & 0.982 & 5.18 & 0.008 & 1.340 & $68.7 \times 10^{-6}$ & 3.066 & 95.56 & 83.6 \\
\hline CR & 1.522 & $64.3 \times 10^{-6}$ & 0.988 & 3.15 & 0.015 & 0.399 & $38.5 \mathrm{e} \times 10^{-6}$ & 2.365 & 118.5 & 73.0 \\
\hline
\end{tabular}




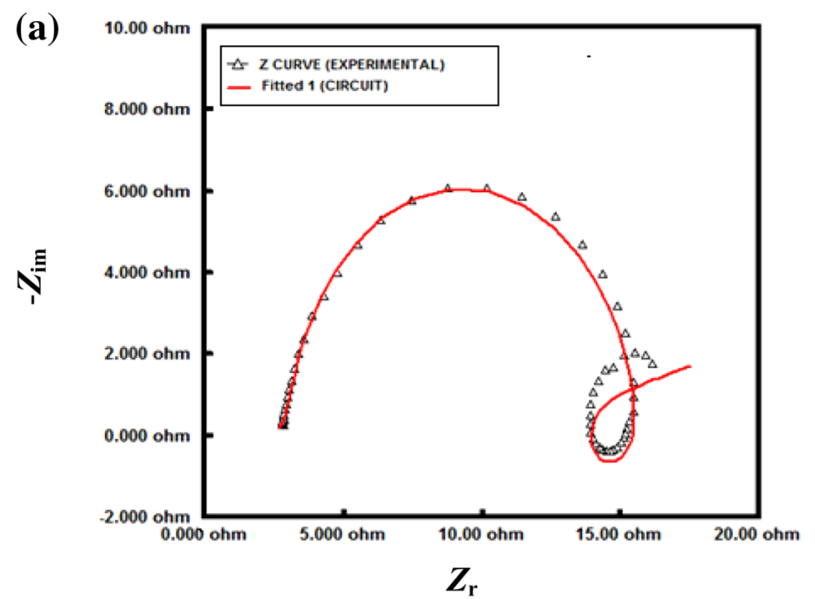

(b)

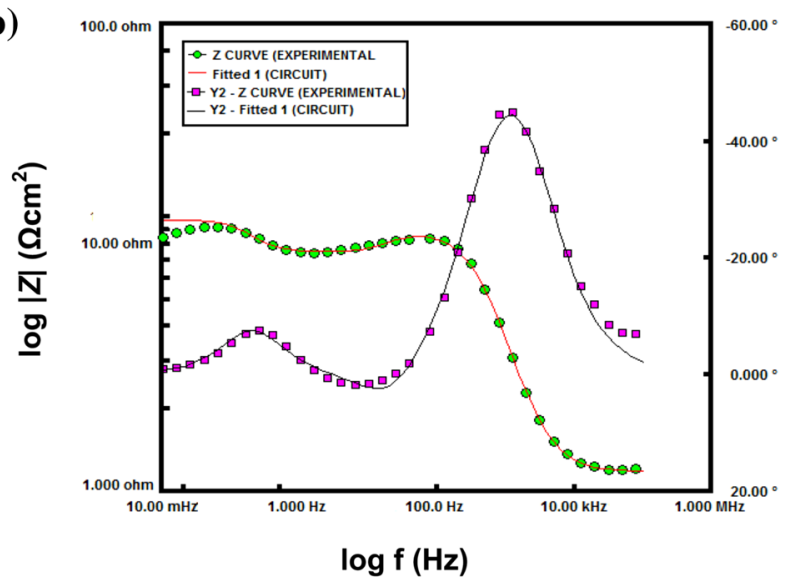

(c)

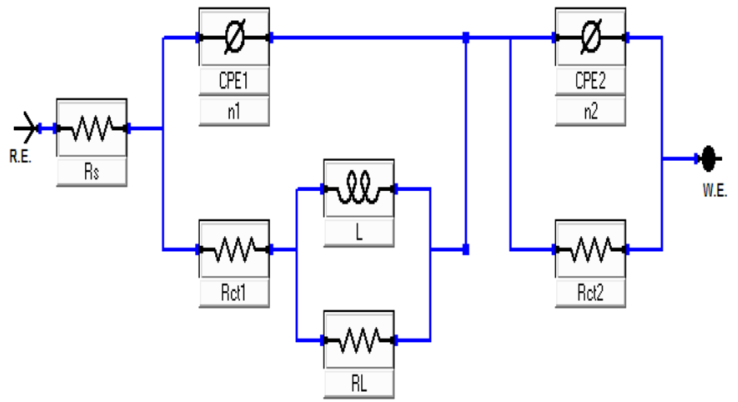

Fig. 4 Simulated and experimentally generated EIS plots. a Nyquist plot angle. b Bode phase angle. c Electrical equivalent circuit used for the analysis of impedance spectra

$Z_{\mathrm{CPE}}=\left(\frac{1}{Q}\right)\left[(j \omega)_{n}\right]^{-1}$

where $Q$ is the proportionality constant comparable to capacitance, $j$ is the imaginary unit, and $\omega$ is the angular frequency $(\omega=2 \pi f, f$ is the frequency at maximum in $\mathrm{Hz})$, $n$ is the phase shift which related to degree of surface nonhomogeneity.

Analysis of Table 2 reveals that the $R_{\mathrm{CT}}$ values in the presence of inhibitors are more than in uninhibited system. The maximum $R_{\mathrm{CT}}$ value was found in the case of PS peel extract, and the increase in values for inhibited system attributed to the decrease in the active surface necessary for the corrosion reaction. The inhibition efficiency associated with charge transfer resistance values is calculated using the following equation:

$\eta \%=\frac{R_{\mathrm{CT}(\mathrm{i})}-R_{\mathrm{CT}(0)}}{R_{\mathrm{CT}(\mathrm{i})}} \times 100$,

where $R_{\mathrm{CT}(\mathrm{i})}$ and $R_{\mathrm{CT}(0)}$ are the charge transfer resistance value with and without inhibitor, respectively.

The value of double layer capacitance $\left(C_{\mathrm{dl}}\right)$ decreases with the increasing inhibitor concentration. The double layer capacitance $\left(C_{\mathrm{dl}}\right)$ term is used to describe the double layer at metal/solution interface by displaying the non-ideal capacitive behavior. The decrease in $C_{\mathrm{dl}}$ value is attributed to the decrease in local dielectric constant or increase in thickness of the electrical double layer suggesting the inhibition action on metal/solution interface. The double layer capacitance $\left(C_{\mathrm{dl}}\right)$ values were calculated using the following equation:

$C_{\mathrm{dl}}=Q\left(\omega_{\max }\right)^{n-1}$,

where $\omega_{\max }$ is the angular frequency at which imaginary element reaches a maximum. Moreover, the addition of inhibitors increases the values of $n$ that explains reduction of surface inhomogeneity due to the adsorption of inhibitor molecules on the most active adsorption sites at the AA surface [34]. Indeed, the lower $n$ value for uninhibited solution $(n=0.975)$ describes a surface inhomogeneity occurring from surface metal roughening and/or surface of corrosion products. The values of $n$ lies between 0.977 and 0.988 in the case of inhibited solutions.

The Bode impedance magnitude and phase angle plots recorded for $\mathrm{AA}$ in $1 \mathrm{M} \mathrm{NaOH}$ in the absence and presence of optimum concentration of inhibitors at its OPC are given in Fig. 5. A linear relationship between $\log |Z|$ and $\log f$, having slope $(S)$ near -1 and the phase angle $\left(\alpha^{\circ}\right)-90^{\circ}$, can be observed in the intermediate frequency region. For an ideal capacitor, the values of $S$ and $\alpha$ should be -1 and $-90^{\circ}$, respectively. However, in this case, the maximum slope value reaches up to -0.71 and the maximum phase angle is $-50^{\circ}$. These deviations are considered to be the deviation from the ideal capacitive behavior at intermediate frequencies [35].

\section{Polarization study}

Tafel polarization study involves in changing the potential of the working electrode and monitoring the current that is produced as a function of time or potential. Tafel polarization curves for aluminum metal in $1 \mathrm{M} \mathrm{NaOH}$ at optimum concentration $(1.5 \mathrm{~g} / \mathrm{L})$ of inhibitors are displayed in Fig. 6. 


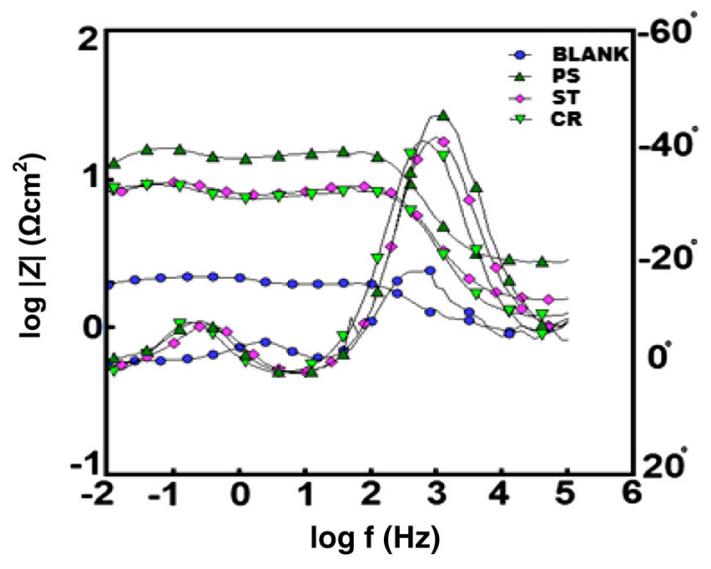

Fig. 5 Bode $(\log f$ vs. $\log |Z|)$ and phase angle $(\log f$ vs. $\alpha$ ) plot of impendence spectra for aluminum in $1 \mathrm{M} \mathrm{NaOH}$ in the absence and presence of optimum concentration of inhibitors at $303 \mathrm{~K}$

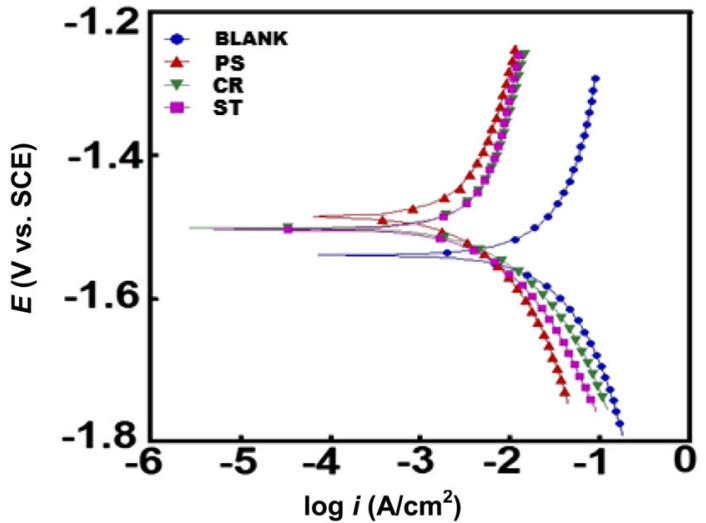

Fig. 6 Tafel curves for aluminum in $1 \mathrm{M} \mathrm{NaOH}$ in the absence and presence of optimum concentration of inhibitors at $303 \mathrm{~K}$

It can be observed from the curves that the presence of inhibitors causes a prominent decrease in corrosion rate, i.e., shifts the anodic curves to more positive potentials and cathodic curves to more negative potentials, and to the lower values of corrosion current densities. In the figure, it is revealed that the addition of inhibitors shifts the cathodic and anodic branches toward lower currents, probably as a consequence of the blocking effect of the adsorbed inhibitor molecules.

The values of polarization parameters such as corrosion potential $\left(E_{\text {corr }}\right)$, anodic and cathodic Tafel slopes $\left(\beta_{\mathrm{a}}\right.$ and $\beta_{\mathrm{c}}$ ), corrosion current density $\left(I_{\text {corr }}\right)$, and inhibition efficiency $(\eta \%)$ are given in Table 3 .

The $\eta \%$ using values of $I_{\text {corr }}$ was calculated using the following equation [36]:

$\eta \%=\frac{I_{\text {corr }}^{0}-I_{\text {corr }}}{I_{\text {corr }}^{0}} \times 100$,

where $I_{\text {corr }}^{0}$ and $I_{\text {corr }}$ are the corrosion current density without and with inhibitor.
As it can be seen from the polarization results (Table 3), the $I_{\text {corr }}$ values in all cases decrease in the presence of all three extracts and this decrease enhances with increase in concentrations. It is obvious that, under the same conditions, the corrosion current decreases in the following order:

$\mathrm{PS}>\mathrm{ST}>\mathrm{CR}$.

This sequence reflects the increased ability of PS peel to inhibit aluminum corrosion in alkaline solutions compared to ST and CR. It is also clear that the values of $b_{\mathrm{a}}$ and $b_{\mathrm{c}}$ slightly changed in the presence of all inhibitors. This suggests that the studied inhibitors were first adsorbed onto the metal surface and impeded by merely blocking the reaction sites of the metal surface without affecting the anodic and cathodic reactions. Table 3 reveals that there is no significant change in the values of $E_{\text {corr }}$ with the inhibitors compared to blank. If the displacement in corrosion potential is more than $0.085 \mathrm{~V}$ with respect to corrosion potential of the blank, the inhibitor can be seen as a cathodic or anodic type [37]. In the present case, the maximum displacement occurs in $E_{\text {corr }}$ of $0.028 \mathrm{~V}$ which is much $<0.085 \mathrm{~V}$, suggesting mixed mode of inhibition.

\section{Linear polarization resistance}

Polarization resistance $\left(R_{\mathrm{p}}\right)$ values were obtained from the resulting plot of current density versus potential. From the measured polarization resistance values, the $\eta \%$ has been calculated using the relation:

$\eta \%=\frac{R_{\mathrm{p}(\mathrm{inh})}-R_{\mathrm{p}}}{R_{\mathrm{p}}} \times 100$,

where $R_{\mathrm{p}}$ and $R_{\mathrm{p}(\mathrm{inh})}$ are polarization resistance in the absence and presence of inhibitors. The calculated values of $R_{\mathrm{p}}$ in $1 \mathrm{M} \mathrm{NaOH}$ solution with the different extracts are shown in Table 3. The linear polarization resistance values $\left(R_{\mathrm{p}}\right)$ are higher in the inhibited system compared to the blank, meaning that lowering of corrosion rate occurs due to the presence of inhibitors. The maximum value is observed in the case of PS, suggesting the formation of its adherent protective film on aluminum surface.

\section{Surface investigations}

\section{Scanning electron microscope}

The SEM images of aluminum in the absence and presence of inhibitors after $3 \mathrm{~h}$ immersion in $1 \mathrm{M} \mathrm{NaOH}$ are displayed in Fig. 7a-d. In the absence of inhibitor, the surface was severely damaged with increasing number of pits and depth and is shown in Fig. 7a. In the presence of CR, ST and PS peel extracts at their optimum concentration ( $1.5 \mathrm{~g} /$ 
Table 3 Electrochemical polarization parameters for AA in $1 \mathrm{M} \mathrm{NaOH}$ in the absence and presence of optimum concentration of inhibitors at $303 \mathrm{~K}$

\begin{tabular}{|c|c|c|c|c|c|c|c|c|}
\hline \multirow[t]{2}{*}{ Inhibitors } & \multicolumn{5}{|c|}{ Tafel polarization } & \multicolumn{3}{|c|}{ Linear polarization } \\
\hline & $\overline{I_{\text {corr }}\left(\mathrm{mAcm}^{-2}\right)}$ & $E_{\text {corr }}(\mathrm{V} / \mathrm{SCE})$ & $\beta_{\mathrm{a}}(\mathrm{V} / \mathrm{dec})$ & $\beta_{\mathrm{c}}(\mathrm{V} / \mathrm{dec})$ & $\overline{\eta(\%)}$ & $R_{\mathrm{p}}\left(\Omega \mathrm{cm}^{-2}\right)$ & $\theta$ & $\eta(\%)$ \\
\hline Blank & 96.3 & -1.508 & 1.001 & 0.504 & - & 1.279 & - & - \\
\hline PS & 5.63 & -1.480 & 0.615 & 0.183 & 94.15 & 14.48 & 0.91 & 91.7 \\
\hline ST & 9.89 & -1.500 & 0.908 & 0.166 & 89.5 & 8.50 & 0.85 & 85.8 \\
\hline $\mathrm{CR}$ & 26.5 & -1.480 & 1.288 & 0.171 & 72.48 & 4.76 & 0.74 & 74.4 \\
\hline
\end{tabular}


Fig. 7 SEM micrographs of a uninhibited and $\mathbf{b}$ inhibited AA sample containing $1.5 \mathrm{~g} / \mathrm{L}$ of CR $\mathbf{c}$ ST d PS in $1 \mathrm{M} \mathrm{NaOH}$

L), the surface roughness has been reduced (Fig. $7 \mathrm{~b}-\mathrm{d}$ ) respectively, which is due to the formation of adsorbed film on it.

\section{Atomic force microscope}

The atomic force microscope gives a powerful means of characterizing the microstructure. The three-dimensional AFM images of AA surface without and with the presence of inhibitors are shown in Fig. 8a-d. In uninhibited solution, AA surface was damaged severely which is attributed to the dissolution of oxide film and the maximum height scale reaches up to $800 \mathrm{~nm}$ (Fig. 8a). When the inhibitor was added to that solution, the surface appeared more flat, homogeneous, and uniform, and the height scale of surface started to decrease. In the case of CR, ST, and PS extracts, the maximum height scales of surface were 200, 120, and $100 \mathrm{~nm}$, respectively (Fig. 8b-d). These results suggested that these extracts showed an appreciable resistance to corrosion.

A diagram is also observed with the help of AFM technique for both uninhibited and inhibited systems, as shown in Fig. 9a-d, which is made along the lines marked in corresponding Fig. 8. This diagram is height histogram, and with this graph, a three-dimensional roughness data were also given in which the values of root-mean-square roughness, $\mathrm{Sq}$ (the average of the measured height deviations taken within the evaluation length and measured from 

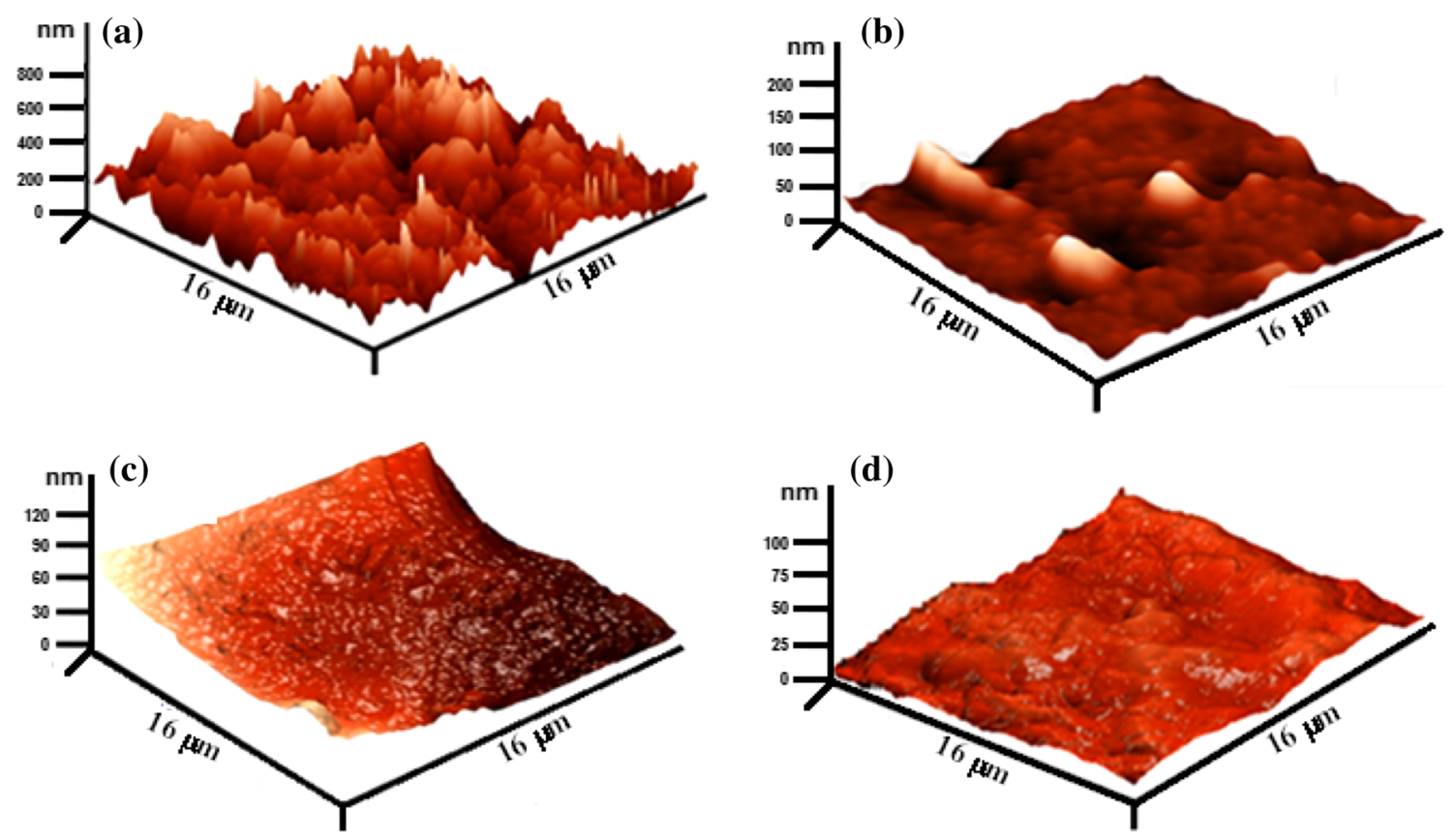

(d)

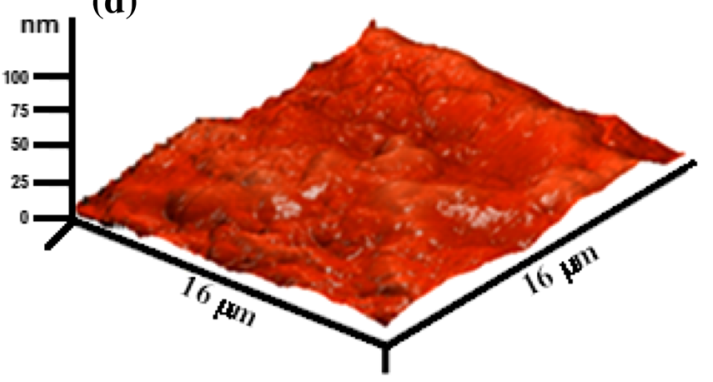

Fig. 8 AFM images of aluminum specimens a uninhibited and b CR c ST d PS in $1 \mathrm{M} \mathrm{NaOH}$


Fig. 9 Height profile diagram of aluminum surface: a uninhibited and b inhibited system containing CR c ST d PS in 1 M NaOH solution

the mean line); average roughness, Sa (the average deviation of all points roughness profile from a mean line over the evaluation length); and St (the maximum peak-to-valley $(\mathrm{P}-\mathrm{V})$ height values; largest single peak-to-valley height in five adjoining sampling heights) for aluminum metal surface in the absence and presence of inhibitors are shown in Table 4. In uninhibited system, the values of Sa, $\mathrm{Sq}$, and $\mathrm{P}-\mathrm{V}$ height are greater (given in Table 4) because of the greater surface roughness of AA. It may be attributed to the dissolution of oxide film layer but the values significantly reduced by the addition of $1.5 \mathrm{~g} / \mathrm{L}$ extracts of PS, ST, and CR peel extracts (Table 4). These parameters confirmed smoother surface due to the formation of a compact protective film on the metal surface, thereby inhibiting the corrosion of aluminum metal. Among the three studied extracts, Pisum Sativum showed the best 
Table 4 AFM data obtained from height profile for aluminum surface immersed in inhibited and uninhibited environments

\begin{tabular}{lccc}
\hline Samples & $\begin{array}{l}\text { RMS (Sq) } \\
\text { roughness (nm) }\end{array}$ & $\begin{array}{l}\text { Average (Sa) } \\
\text { roughness (nm) }\end{array}$ & $\begin{array}{l}\text { Area (St) } \\
\text { peak-to-valley (nm) }\end{array}$ \\
\hline Aluminum metal Immersed in 1 M NaOH solution & 109.99 & 87.30 & 806.23 \\
Metal immersed in 1 M NaOH solution containing CR peel extract & 45.98 & 30.26 & 368.75 \\
Metal immersed in 1 M NaOH solution containing ST peel extract & 3.07 & 1.80 & 186.16 \\
Metal immersed in 1 M NaOH solution containing PS peel extract & 2.87 & 1.41 & 102.50 \\
\hline
\end{tabular}

Table 5 Molecular structure of major constituents present in extracts

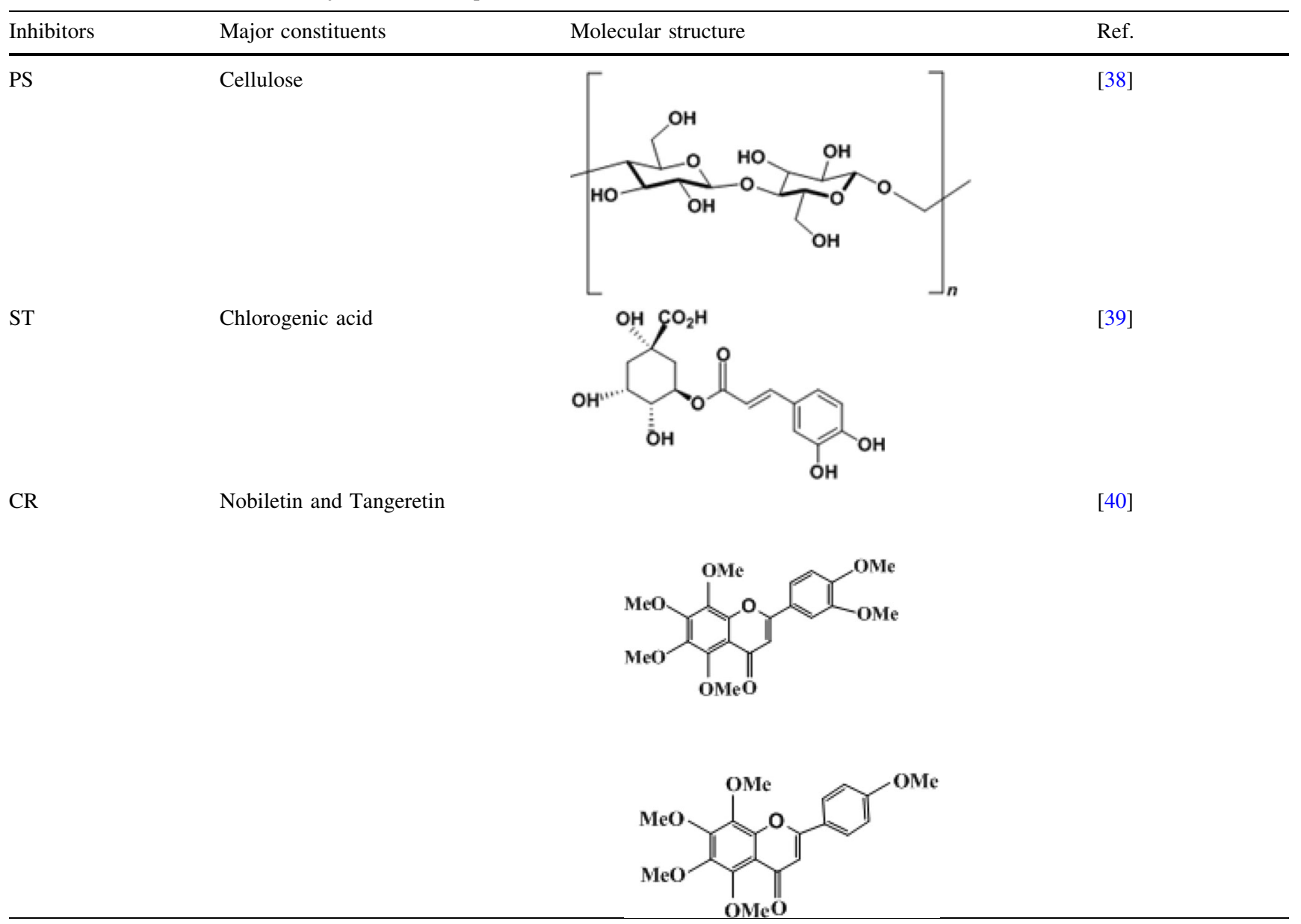

inhibiting action which was confirmed by the maximum reduction in $\mathrm{Sa}, \mathrm{Sq}$, and $\mathrm{RMS}$ values.

\section{Explanation for inhibition}

The extract of peels in our study contains various naturally occurring compounds. PS peel extract contains cellulose and hemicelluloses in essential amounts [38]. The molecular structure of cellulose is given in Table 5. The aqueous extract of potato peel contains polyphenolic compound with an antioxidation potential. Potato peel contains phenolic acids. The largest part consists of chlorogenic acid [39] whose molecular structure is presented in the table, and nobiletin and tangeretin are identified in aqueous extract of citrus peels and are considered as the main functional components [40].

Because of the presence of heteroatoms, functional groups, and pi-electrons in these chemical constituents, corrosion inhibition by aqueous peel extracts can be regarded as synergistic process. Some of the structures of these constituents of peel extract are given in Table 5. The high inhibition efficiency shown by these peel extracts can 
be attributed to the presence of $-\mathrm{OH}$ and $-\mathrm{COOH}$ groups being de-protonated in alkaline medium, remaining in the form of anionic species. The anionic species of these constituent molecules adsorb more closely and strongly on the AA surface. Thus, it can be explained that the inhibitor molecules adsorb chemically on the AA surface in alkaline medium which is also confirmed experimentally that with increasing temperature, there is no increase in inhibition performance.

The adsorption of inhibitor molecules on metal surface is considered as a displacement reaction involving the removal of $\mathrm{H}_{2} \mathrm{O}$ molecules from the metal surface and adsorption of inhibitor molecules on metal surface [41] :

Inhibitor $_{(\text {sol })}+n \mathrm{H}_{2} \mathrm{O}_{(\text {ads })} \leftrightarrow$ Inhibitor $_{(\text {ads })}+n \mathrm{H}_{2} \mathrm{O}_{(\text {sol })}$

The order of the inhibition performances of peel extract is as follows:

PS $>$ ST $>$ CR.

The high performance of Pisum sativum extract could also be due to the large size of the constituent molecules, which cover wide areas on the metal surface, thus retarding corrosion [42].

\section{Conclusion}

1. Among the studied peel extracts, PS was found to be the best inhibitor for AA in alkaline solution.

2. Inhibition efficiency increases with an increase in concentration of extracts. PS showed the maximum efficiency $(94.5 \%)$ at its optimum concentration $(1.5 \mathrm{~g} / \mathrm{L})$.

3. Langmuir adsorption isotherm and impedance studies showed that PS, ST, and CR inhibit the corrosion of AA through adsorption mechanism.

4. All the inhibitors acted as mixed-type by inhibiting anodic and cathodic reactions to nearly the same extent.

5. The SEM and AFM analyses with height profile diagram showed that the addition of the peel extract to the corrosive medium results in the formation of a protective film on the AA surface.

Acknowledgments The authors are highly thankful to Prof. R. K. Mandal, Head (Department of metallurgical Engineering) I.I.T. (B.H.U.) and Prof. V. B. Singh, Head (Department of chemistry), B.H.U. for providing SEM and AFM facilities for successful completion of my research work.

\section{Compliance with ethical standards}

Conflict of interest The authors declare that they have no conflict of interest.
Open Access This article is distributed under the terms of the Creative Commons Attribution 4.0 International License (http://crea tivecommons.org/licenses/by/4.0/), which permits unrestricted use, distribution, and reproduction in any medium, provided you give appropriate credit to the original author(s) and the source, provide a link to the Creative Commons license, and indicate if changes were made.

\section{References}

1. Gupta M, Mishra J, Pitre KS (2014) Corrosion and inhibition behavior of aluminium in alkaline medium and sodium silicate. IJOART 3:50-59

2. Soliman HN (2011) Influence of 8-hydroxyquinoline addition on the corrosion behavior of commercial $\mathrm{Al}$ and $\mathrm{Al}-\mathrm{HO} 411$ alloys in $\mathrm{NaOH}$ aqueous media. Corros Sci 53:2994-3006

3. Mercier D, Barthes-Labrousse MG (2009) The role of chelating agents on the corrosion mechanisms of aluminium in alkaline aqueous solutions. Corros Sci 51:339-348

4. Onuchukwu AI (1990) The inhibition of aluminium corrosion in an alkaline medium II: Influence of hard bases. Mat Chem Phys 24:337-341

5. Pyun SI, Moon SM, Ahn SH, Kim SS (1999) Effects of $\mathrm{Cl}^{-}$, $\mathrm{NO}^{-3}$ and $\mathrm{SO}_{2}^{-4}$ ions on anodic dissolution of pure aluminum in alkaline solution. Corros Sci 41:653-667

6. Rosilda LGS, Ganesan M, Kulandainathan MA, Kapali V (1994) Influence of inhibitors on corrosion and anodic behaviour of different grades of aluminium in alkaline media. J Power Sources 50:321-329

7. Krishnan M, Subramanyan N (1977) The influence of some aldehydes on the corrosion and anodic behavior of aluminium in sodium hydroxide solution. Corros Sci 17:893-900

8. Abiola OK, Otaigbe JOE, Kio OJ (2009) Gossipium hirsutum L. extracts as green corrosion inhibitor for aluminum in $\mathrm{NaOH}$ solution. Corros Sci 51:1879-1881

9. Saleh M, Ismail AA, El Hosary AA (1983) Corrosion inhibition by naturally occurring substances-IX. The effect of the aqueous extracts of some seeds, leaves, fruits and fruit-peels on the corrosion of $\mathrm{Al}$ in $\mathrm{NaOH}$. Corros Sci 23:1239-1241

10. Abiola OK, Otaigbe JOE (2009) The effects of Phyllanthus amarus extract on corrosion and kinetics of corrosion process of aluminum in alkaline solution. Corros Sci 51:2790-2793

11. Abdel-Gaber AM, Khamis E, Abo-ElDahab H, Adeel S (2008) Inhibition of aluminium corrosion in alkaline solutions using natural compound. Mat Chem Phys 109:297-305

12. Noor EA (2009) Potential of aqueous extract of Hibiscus sabdariffa leaves for inhibiting the corrosion of aluminum in alkaline solutions. J Appl Electrochem 39:1465-1475

13. Emran KM, Ahmed NM, Torjoman BA, Al-Ahmadi AA, Sheekh SN (2014) Cantaloupe extracts as eco friendly corrosion inhibitors for aluminum in acidic and alkaline solutions. J Mater Environ Sci 5:1940-1950

14. James AO, Akaranta $\mathrm{O}$ (2014) Corrosion inhibition of aluminium in $2 \mathrm{M}$ sulphuric acid using acetone extract of red onion skin. Int J Appl Chem Sci Res 2:1-10

15. Sangeetha M, Rajendran S, Sathiyabam J, Prabhakar P (2012) Eco friendly extract of Banana peel as corrosion inhibitor for carbon steel in sea water. J Nat Prod Plant Resour 2:601-610

16. Gunavathy N, Murugavel SC (2012) Corrosion inhibition studies of mild steel in acid medium using musa acuminata fruit peel extract. E-J. Chem 9:487-495

17. Eddy NO, Ebenso EE (2008) Adsorption and inhibitive properties of ethanol extract of Musa sapientum peels as a green corrosion inhibitor for mild steel in $\mathrm{H}_{2} \mathrm{SO}_{4}$. Afr J Pure Appl Chem 2:46 
18. Ibrahim T, Habbab M (2011) Corrosion inhibition of mild steel in $2 \mathrm{M} \mathrm{HCl}$ using aqueous extract of eggplant peel. Int J Electrochem Sci 6:5357-5371

19. El-Haddad MN, Fouda AS (2013) Inhibition effect and adsorption behavior of new azodye derivatives on corrosion of carbon steel in acid medium. J Dispers Sci Technol 34:1471-1480

20. Chakravarthy MP, Mohana KN, Kumar CBP (2014) Corrosion inhibition effect and adsorption behavior of nicotinamide derivatives on mild steel in hydrochloric acid solution. Int J Ind Chem 5:19-38

21. Akalezi CO, Enenebaku CK, Oguzie EE (2012) Application of aqueous extracts of coffee senna for control of mild steel corrosion in acidic environments. Int $\mathrm{J}$ Ind Chem 3:13-25

22. Sabirneeza AAF, Subhashini S (2014) Poly(vinyl alcohol-proline) as corrosion inhibitor for mild steel in $1 \mathrm{M}$ hydrochloric acid. Int J Ind Chem 5:111-120

23. Mobin M, Khan MAK (2013) Investigation on the adsorption and corrosion inhibition behavior of gum acacia and synergistic surfactants additives on mild steel in $0.1 \mathrm{M} \mathrm{H}_{2} \mathrm{SO}_{4}$. J Dispers Sci Technol 34:1496-1506

24. Madkour LH, Elroby SK (2015) Inhibitive properties, thermodynamic, kinetics and quantum chemical calculations of polydentate Schiff base compounds as corrosion inhibitors for iron in acidic and alkaline media. Int J Ind Chem. doi:10.1007/s40090015-0039-7

25. Shao HB, Wang JM, Zhang Z, Zhang JQ, Cao CN (2003) The cooperative effect of calcium ions and tartrate ions on the corrosion inhibition of pure aluminum in an alkaline solution. Mat Chem Phys 77:305-309

26. Abdel-Gaber AM, Khamis E, Abo-EIDahab S, Adeel H (2008) Inhibition of aluminium corrosion in alkaline solutions using natural compound. Mat Chem Phys 109:297-305

27. Yadav DK, Quraishi MA (2012) Application of some condensed uracils as corrosion inhibitors for mild steel: gravimetric, electrochemical, surface morphological, uv-visible and theoretical investigations. Ind Eng Chem Res 51:14966-14979

28. Mansfeld F, Lin S, Kim S, Shih H (1987) Pitting and surface modification of SIC/Al. Corros Sci 27:997-1000

29. Brett CMA (1990) The application of electrochemical impedance techniques to aluminium corrosion in acidic chloride solution. J Appl Electrochem 20:1000-1003

30. Brett CMA (1992) On the electrochemical behavior of aluminium in acidic chloride solution. Corros Sci 33:203-210
31. Khaled KF (2010) Electrochemical investigation and modeling of corrosion inhibition of aluminum in molar nitric acid using some sulphur-containing amines. Corros Sci 52:2905-2916

32. Emregul KC, Aksut AA (2000) The behavior of aluminum in alkaline media. Corros Sci 42:2051-2067

33. Amin MA, Khaled KF, Mohsen Q, Arida HA (2010) A study of the inhibition of iron corrosion in $\mathrm{HCl}$ solutions by some amino acids. Corros Sci 52:1684-1695

34. Yadav DK, Chauhan DS, Ahamad I, Quraishi MA (2013) Electrochemical behavior of steel/acid interface: adsorption and inhibition effect of oligomeric aniline. RSC Adv 3:632-646

35. Ansari KR, Sudheer Singh A, Quraishi MA (2014) Some pyrimidine derivatives as corrosion inhibitor for mild steel in hydrochloric acid. J Dispers Sci Technol 36:908-917

36. Bahrami MJ, Hosseini SMA (2012) Electrochemical and thermodynamic investigation of the corrosion behavior of mild steel in $1 \mathrm{M}$ hydrochloric acid solution containing organic compounds. Int J Ind Chem 3:30-39

37. Ansari KR, Yadav DK, Ebenso EE, Quraishi MA (2012) Novel and effective pyridyl substituted 1,2, 4-triazole as corrosion inhibitor for mild steel in acid solution. Int J Electrochem Sci 7:4780-4799

38. Verma N, Bansal MC, Kumar V (2011) Pea peel waste: a lignocellulosic waste and its utility in cellulose production by trichoderma reesei under solid state cultivation. BioResources 6:1505-1519

39. Ibrahim TH, Chehade Y, Zour MA (2011) Corrosion inhibition of mild steel using potato peel extract in $2 \mathrm{M} \mathrm{HCl}$ solution. Int $\mathrm{J}$ Electrochem Sci 6:6542-6556

40. Tumbas VT, Cetkovic GS, Djilas SM, Canadanovic-Brunet JM, Vulic JJ, Knez Z, Skerget M (2010) Antioxidant activity of mandarin (Citrus reticulata) peel. Acta Periodica Technologica 40:195-203

41. Prabhu D, Rao P (2013) Coriandrum sativum L.-A novel green inhibitor for the corrosion inhibition of aluminium in $1.0 \mathrm{M}$ phosphoric acid solution. J Environ Chem Eng 1:676-683

42. Singh A, Ahamad I, Yadav DK, Singh VK, Quraishi MA (2012) The effect of environmentally benign fruit extract of shahjan (Moringa oleifera) on the corrosion of mild steel in hydrochloric acid solution. Chem Eng Comm 199:63-77 